\section{Cureus}

\title{
Intrapelvic Localised Hydatid Cyst
}

Murat F. Ferhatoglu Assistant Professor ${ }^{1}$, Ali I. Filiz ${ }^{2}$

1. General Surgery, Okan University Medical Faculty, Istanbul, TUR 2. General Surgery, Okan University, Istanbul, TUR

$\square$ Corresponding author: Murat F. Ferhatoglu Assistant Professor, ferhatferhatoglu@yahoo.co.uk Disclosures can be found in Additional Information at the end of the article

\section{Abstract}

Hydatid cysts, caused by Echinococcus granulosus, is an important health problem in endemic areas. The disease can localize most commonly in the liver and lungs. Primary pelvic involvement is a rare condition. In this case report, we aimed to present a 75-year-old male patient with a pelvic mass, which was diagnosed preoperatively as a hydatid cyst.

Categories: General Surgery, Public Health

Keywords: echinococcus granulosus, pelvic, hydatic cyst

\section{Introduction}

Hydatid cyst disease is endemic to the Middle East, South America, East Africa, and the Mediterranean countries [1]. Sheep, pig, goat, and man are intermediate hosts, harboring the larval stage. Adult forms of Echinococcus granulosus parasites live in the intestines of dogs. The eggs formed by the adult forms are absorbed by people's mouths when they eat contaminant foods that are infested with dog feces. Once the eggs open in the human stomach, they spread through the blood and can form cystic structures in all organs [2]. The most frequently observed organs with this cystic formation are the liver and lungs [3]. Primary pelvic involvement is a rare condition. In this case report, we aimed to present a 75-year-old-male patient with a pelvic mass that was diagnosed preoperatively as hydatid cyst disease.

\section{Case Presentation}

A 75-year-old Iraqi male presented to the surgery clinic with chronic abdominal and right inguinal pain. He did not have a history of any surgery or trauma and was taking amlodipine 10 $\mathrm{mg}$ for hypertension. On examination, the patient's blood pressure was 135/95 $\mathrm{mm} \mathrm{Hg}$, heart rate was $62 \mathrm{bpm}$, and body temperature was $36.8^{\circ} \mathrm{C}$. His abdominal examination did not reveal any signs of rigidity, rebound, or pulsatile mass. The laboratory examination findings were: leukocyte: 7300/mm3(4600-10200/mm3), c-reactive protein: $2.7 \mathrm{mg} / \mathrm{dL}(0-5 \mathrm{mg} / \mathrm{dL})$, potassium: $3.8 \mathrm{mmol} / \mathrm{dL}$ (3.5-5.1 $\mathrm{mmol} / \mathrm{dL})$, aspartate aminotransferase: $34 \mathrm{U} / \mathrm{L}$ (5-34 U/L), and alanine aminotransferase: $205 \mathrm{U} / \mathrm{L}$ (0-55 U/L). Plain abdominal X-ray and ultrasonography did not reveal any abnormality. Intravenous contrast-enhanced computed tomography (CECT) scan revealed a calcified mass that was $60 \times 52 \mathrm{~mm}$ in size and localized between the right internal iliac artery and urinary bladder (Figure 1). The Tru-cut biopsy of the mass was undiagnostic and did not reveal if the mass was benign or malignant. It was decided to take the surgical approach. An explorative laparotomy was performed with a vertical midline incision. A lesion that was $5 \times 4 \mathrm{~cm}$ in diameter and localized in the retroperitoneal area, between the right internal iliac artery and the urinary bladder, was excised (Figures 2-3). The frozen section pathological examination of the mass revealed that it was a pelvic hydatid cyst. Definitive 


\section{Cureus}

pathological results also confirmed the results of the frozen section. On the first day after the surgery, a liquid diet was given. His vital signs were normal on follow-up, and he was discharged uneventfully on the fourth day of the operation. Albendazole $200 \mathrm{mg} / \mathrm{day}$ was prescribed to the patient.

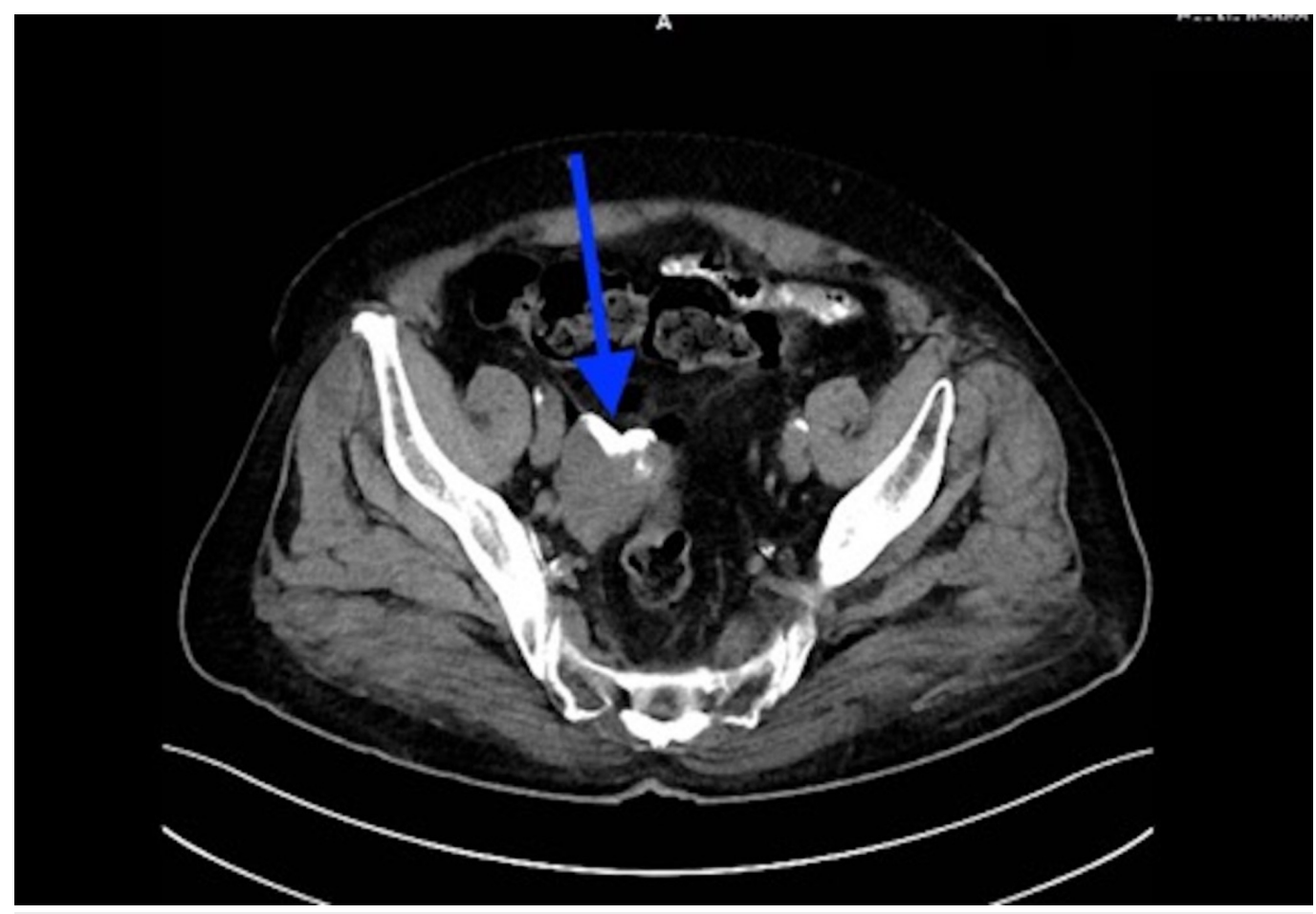

FIGURE 1: Computed tomography image, $5 \times 4 \mathrm{~cm}$ calcified mass (blue arrow)

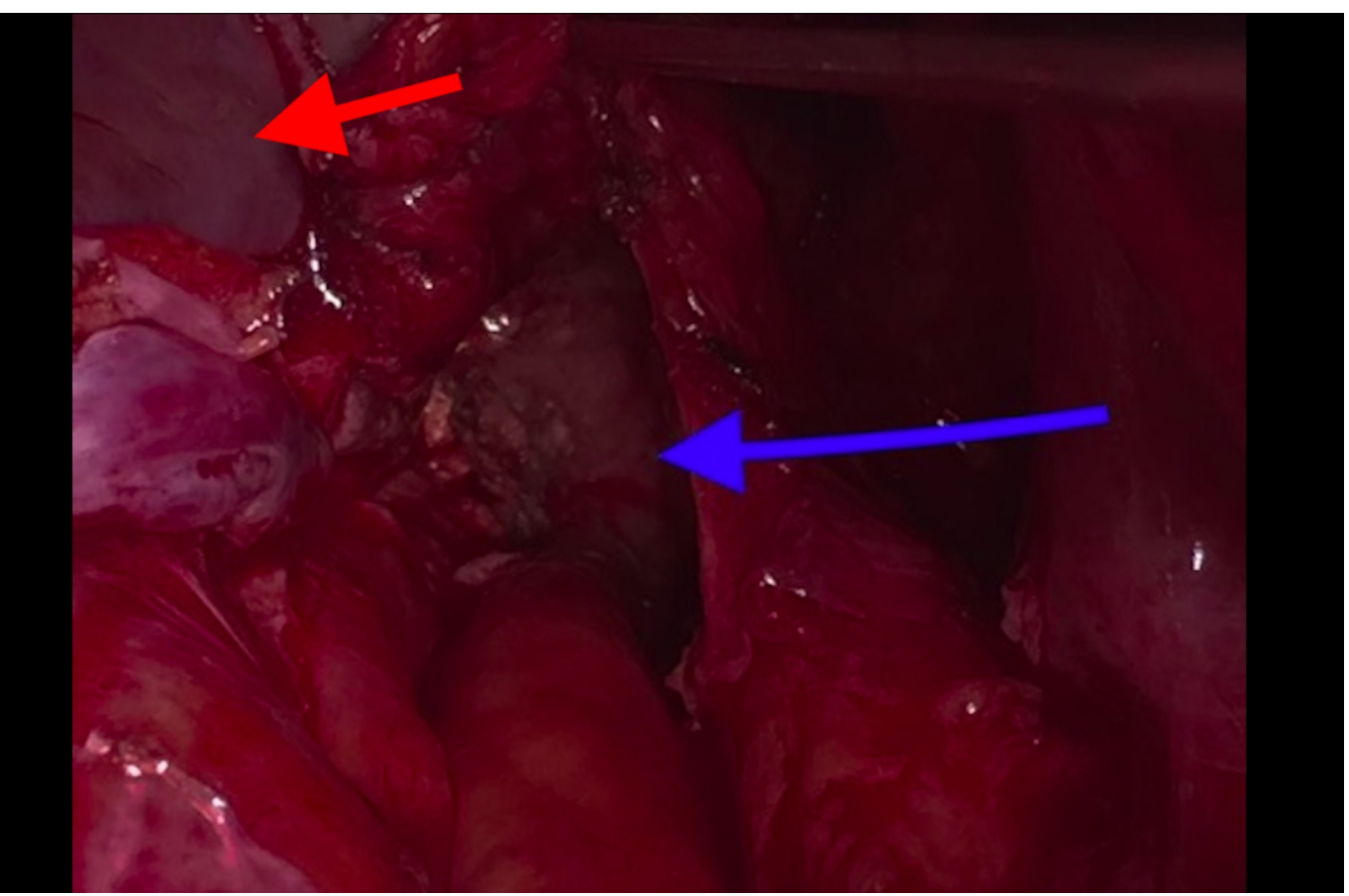

FIGURE 2: Deep pelvic localization of hydatid cyst (blue arrow), 


\section{Cureus}

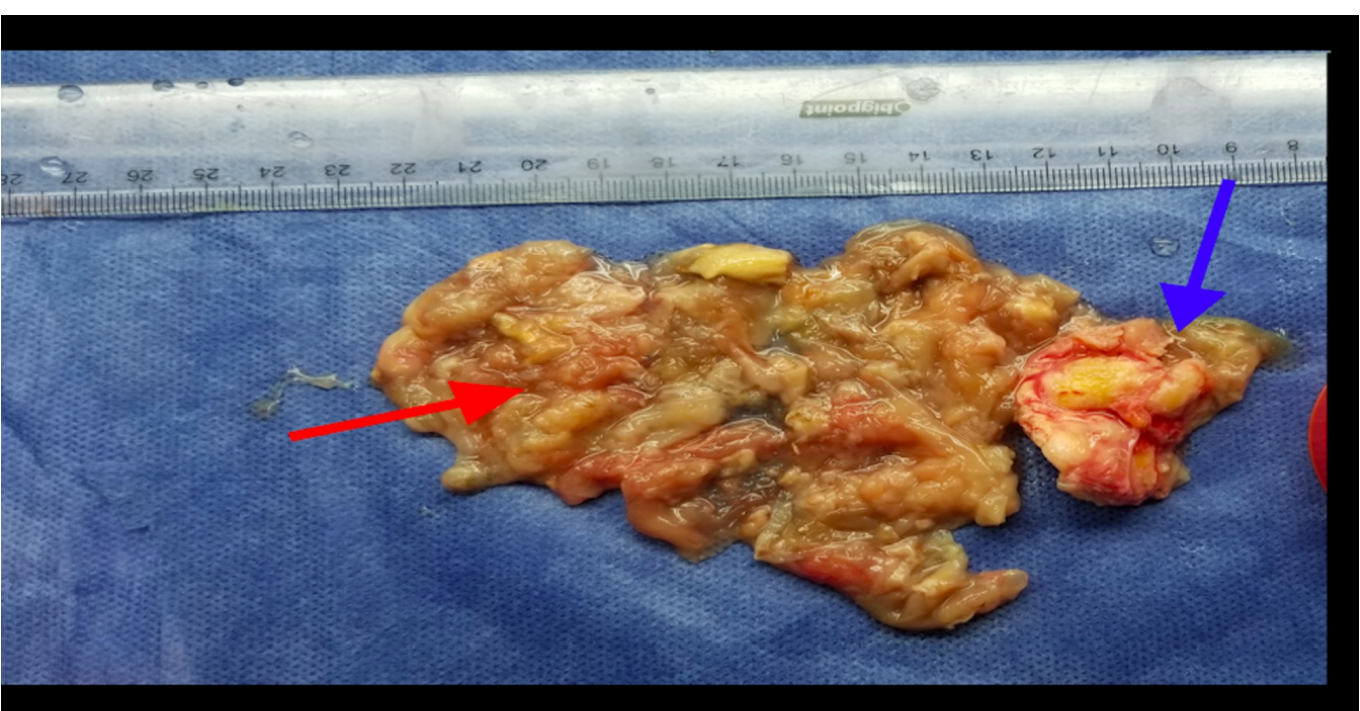

FIGURE 3: Excised specimen of cyst. Calcified cyst wall (blue arrow), dead membranes of daughter vesicles (red arrow)

\section{Discussion}

Echinococcus granulosus is a parasite that causes hydatid cyst disease. This infection is usually observed in people who have close contact with dogs and sheep [4]. The disease is endemic in the Middle East, South America, East Africa, and the Mediterranean countries. The most common localizations of this disease are the liver and lung. Hydatid cyst disease is rarely observed in the pelvis, and the incidence is between $0.20 \%$ and $2.25 \%$ [5]. The cases are usually secondary to the rupture of a hydatid cyst localized in the liver. Primary pelvic hydatid cyst is rarely found and a small number of pelvic localized hydatid cyst cases have been reported in the literature [6]. These events may occur when the parasite reaches the pelvis by hematogenous or through the lymphatic route.

Symptoms are non-specific but the main symptom is pelvic pain. Symptoms are related to pressure. Menstrual irregularity in females and infertility can be observed [7]. On physical examination, there are no specific findings. A palpable pelvic mass can be detected [5]. Ovarian cyst, mesenteric cyst, gastrointestinal duplication cyst, cystadenoma, and lymphangioma should be kept in mind in the differential diagnosis [8]. Cysts can sometimes spontaneously rupture, and a serious anaphylactic reaction may develop in this situation.

Serological tests may be helpful in the diagnosis, but even they are not a $100 \%$ reliable [9]. The disease can be detected by imaging methods. Because of its low cost and easy accessibility, ultrasonography is preferred as the first imaging method [7]. Computed tomography may provide better information about cyst morphology and is more successful in showing the calcification and morphology of cysts [10]. Magnetic resonance imaging (MRI) may provide some advantages over computed tomography (CT) for identifying residual lesions and recurrences, especially after surgery [3].

Mebendazole or albendazole treatment is successful in the majority of the cases, but medical 
therapy should not be preferred as the primary treatment method except in cases where the patient is not suitable for the surgical approach or the cyst size is small or deeply located. Surgical treatment is the most effective method. A combination of preoperative drugs with surgery and postoperative medical therapy is the preferred regime [9]. It has been reported that the use of mebendazole or albendazole reduces the risk of recurrence from $80 \%$ to $10 \%$ and albendazole is the most effective medical treatment agent for Echinococcus granulosus [11].

En bloc resection without rupture or spreading of the daughter cyst is the recommended treatment strategy [12]. The use of scolicidal agents before the cyst membrane is opened during surgery is recommended to kill daughter vesicles, for preventing the spread of the cyst fluid, which may cause an anaphylactic reaction [13].

Albendazole or mebendazole should be used in postoperative treatment. Albendazole given preoperatively in a dose of $10 \mathrm{mg} / \mathrm{kg} /$ day for one month kills most of the protoscoleces within the hepatic hydatid cyst. Ultrasonography and serological tests are useful in postoperative follow-ups [14].

\section{Conclusions}

A primary pelvic hydatid cyst is rarely seen, and it should be considered in the differential diagnosis of pelvic masses, especially in those who live in or travel to endemic areas. In addition, the disease might not be diagnosed in the preoperative period despite all radiological and laboratory methods.

\section{Additional Information \\ Disclosures}

Human subjects: Consent was obtained by all participants in this study. Conflicts of interest: In compliance with the ICMJE uniform disclosure form, all authors declare the following: Payment/services info: All authors have declared that no financial support was received from any organization for the submitted work. Financial relationships: All authors have declared that they have no financial relationships at present or within the previous three years with any organizations that might have an interest in the submitted work. Other relationships: All authors have declared that there are no other relationships or activities that could appear to have influenced the submitted work.

\section{References}

1. Yaman I, Inceboz U, Inceboz T, Keyik B, Uzgoren E: Primary pelvic cystic Echinococcosis [Article in Turkish]. Turkiye Parazitol Derg. 2015, 39:167-170. 10.5152/tpd.2015.3623

2. Singh P, Mushtaq D, Verma N, Mahajan NC: Pelvic hydatidosis mimicking a malignant multicystic ovarian tumor. Korean J Parasitol. 2010, 48:263-265. 10.3347/kjp.2010.48.3.263

3. Benkaddour YA, Mansouri MZ, Rabbani K, Jalal H, Aboulfalh A, Abbassi H: Primary pelvic hydatid cyst an unusual cause of cystic adnexal image (mass). AJRH. 2011, 15:165-168.

4. Abike F, Dunder I, Tapisiz LO, Temizkan O, Bingol B, Payasli A, Kutlay L: Primary pelvic hydatic cyst mimicking ovarian carcinoma. J Chin Med Assoc. 2011, 74:237-239. 10.1016/j.jcma.2011.03.011

5. Chelli D, Methni A, Gatri C, Boudaya F, Affes M, Chennoufi MB: Pelvic hydatid (echinococcal) disease. Int J Gynaecol Obstet. 2010, 109:45-48. 10.1016/j.ijgo.2009.10.021

6. Bouihi J, Moustaide H, Amrani BE, Mimouni A: Primary pelvic hydatid cyst: about a case [Article in French]. Pan Afr Med J. 2016, 25:239. 10.11604/pamj.2016.25.239.11238

7. Doğan K, Kaya C, Karaman Ü, Kalaycı MU, Baytekin HF: Nadir bir olgu: tuboovaryan apseye neden olan hidatik kist [Article in Turkish]. Mikrobiyol Bul. 2013, 47:356-361.

8. Majbar MA, Souadka A, Sabbah F, Raiss M, Hrora A, Ahallat M: Peritoneal echinococcosis: anatomoclinical features and surgical treatment. World J Surg. 2012, 36:1030-1035. 


\section{Cureus}

\subsection{7/s00268-012-1475-6}

9. Parray FQ, Wani SN, Bazaz S, Khan SR, Malik SN: Primary pelvic hydatid cyst: a case report . Case Rep Surg. 2011, 2011:809387. 10.1155/2011/809387

10. Sable S, Mehta J, Yadav S, Jategaokar P, Haldar PJ: Primary omental hydatid cyst: a rare entity . Case Rep Surg. 2012, 2012:654282. 10.1155/2012/654282

11. Güngör T, Altınkaya SÖ, Sırvan L, Lafuente RA, Ceylaner S: Coexistence of borderline ovarian epithelial tumor, primary pelvic hydatid cyst, and lymphoepithelioma-like gastric carcinoma. Taiwan J Obstet Gynecol. 2011, 50:201-204. 10.1016/j.tjog.2009.10.005

12. Parray FQ, Ahmad SZ, Sherwani AY, Chowdri NA, Wani KA: Primary paraspinal hydatid cyst: a rare presentation of echinococcosis. Int J Surg. 2010, 85:404-406. 10.1016/j.ijsu.2010.04.011

13. Gorad K, Rayate N, Oswal K, Krishna A, Deshmukh A, Rajmanickam S, Puntambekar S: Laparoscopic removal of pelvic hydatid cysts in young female: a case report . Minim Invasive Surg. 2011, 2011:346828. 10.1155/2011/346828

14. Bari SU, Arif SH, Malik AA, Khaja AR, Dass TA, Naikoo ZA: Role of albendazole in the management of hydatid cyst liver. Saudi J Gastroenterol. 2011, 17:343-347. 10.4103/13193767.84493 